\title{
Voltas em torno de algumas personagens femininas em canções de Chico Buarque
}

\section{Atilio Bergamini Junior ${ }^{*}$}

\begin{abstract}
Resumo: o artigo estuda algumas personagens Abstract: the present work makes an analysis of how femininas em canções de Chico Buarque. A partir de females characters are constructed in a few of the regularidades discursivas, trata-se de explicar e Chico Buarque's songs. It tries to understand some interpretar a recorrência de estereótipos que percebem stereotypes that construct the women as people without as mulheres como fracas de entendimento. intelligence.
\end{abstract}

Palavras-chave: Chico Buarque; canção; estereótipos. Keywords: Chico Buarque; song; stereotypes.

Recorre, nos últimos anos, o discurso de que abordagens acadêmicas das obras de Chico Buarque são parciais e redutoras. Conforme esse discurso, a academia atenta para aspectos sem estabelecer um entendimento integrador, "mutilando" a obra. O problema é que o discurso que acusa a academia, partindo muitas vezes do jornalismo, via de regra não supera os procedimentos acadêmicos, seja em propostas teóricas, seja em aprofundamento metodológico ou mesmo em compreensão dos próprios limites analíticos.

Se é certo que as abordagens acadêmicas devem ser criticadas e reformuladas, também é certo que, de um modo geral, os trabalhos acadêmicos têm sido flexíveis quanto a atualizações e remodelações, bem como têm partido de uma gama de métodos, abordagens, teorias e especulações que mesclam (ou optam por) vieses semânticos, discursivos, marxistas, feministas, musicais, literários e psicanalíticos (por Freud, por Lacan, por Klein, por Jung). A economia, a política, a política da sexualidade, uma sexualidade política, a mulher como voz, a mulher como objeto, o homem, o malandro, o lirismo, o samba. Não se nota, ao menos em termos de superfície, algo como falta de pluralidade nas abordagens. Além disso, a parcialidade entendida como exagerada pode se transformar, quando reposta no horizonte amplo das análises, numa profícua opção, qual seja, a de aprofundar os particulares para

\footnotetext{
* Mestrando em literatura brasileira na Universidade Federal do Rio Grande do Sul. Estuda as relações entre estrutura social e estrutura literária. Atualmente trabalha na obra de Machado de Assis. Email: atiliobergamini@yahoo.com.br
} 
melhor compreender a obra, suas condições de produção e sua ressonância política. A possível mutilação, vista de outro ângulo, pode significar abrangência.

Entendo como desmedida a postura que nega todos esses esforços, entendendo-os como se fossem uma só coisa, meras modas analíticas (embora elas existam, é claro). Se há limites nas análises acadêmicas, eles também estão dados para outras análises, não acadêmicas. Não se lida com os limites de um método, de uma abordagem, de uma interpretação, de uma análise, sem primeiro reconhecê-los na própria análise. Reconhecê-los nas análises dos colegas que estudam aspectos do mesmo tema faz parte deste caminho, mas não é sua conclusão. Colocar-se acima de todos os demais e acima das condições objetivas de produção teórica faz lembrar a atitude da elite diagnosticada por Antonio Candido (1995), que parecia compensar a falta de profundidade do próprio conhecimento criticando o que se produzia no Brasil como se fosse menor e indigno de comparação com a "civilização" européia.

Por outro lado, não cabe, é claro, qualquer tipo de deslumbre a respeito das pesquisas acadêmicas. Quando construímos pluralidade, podemos, quem sabe, ser dispersivos. Quando alcançamos aprofundamento metodológico, podemos, às vezes, ecoar superficialidade histórico-crítica. São questões que precisam ser entendidas caso a caso. Pensar não se torna mais complexo quando simplifica o pensamento "outro".

Com essa crítica-autocrítica em mente, começo uma análise que tenta compreender como personagens femininas de algumas canções de Chico Buarque lêem o mundo. O tema parece abrangente e desfocado, mas, quando localizado de canção em canção, ele se ajusta: primeiramente, vou lidar com a leitura que uma personagem faz de um sonho; em seguida, com a leitura que outra personagem faz de um filme; de modo mais ligeiro, lidarei com o modo como personagens das canções percebem a televisão e, para concluir, analisarei a leitura que uma personagem faz da realidade que a circunda. Sinto por deixar de lado uma leitura musical das canções. Ela é tão ou mais fundamental do que a leitura e análise das letras, mas exige um conhecimento que não possuo. Por esse motivo, parto de um ponto-devista que não passa de um dos momentos de leitura das canções de Chico Buarque. Um segundo momento, conjugado dialeticamente com esse primeiro, terá que esperar alguns anos, até que meu ouvido se eduque um pouco mais.

Veremos que, quanto às personagens de Chico Buarque, faz toda a diferença elas serem homens ou mulheres e, ao serem mulheres, veremos que a forma das canções deixa notar uma recorrência: a identificação de criadores homens com personagens femininas; identificação que, no Japão, perspassa a obra de um Kawabata Yasunari e que, no Brasil, é 
saliente na recepção das canções de Chico Buarque (me pergunto se é, de forma tão saliente, na própria obra). Na história da literatura européia, o procedimento está exemplificado na frase de Flaubert: Madame Bovary c'est moi.

Uma das canções que Chico Buarque produziu para ser trilha sonora de um filme, Não sonho mais $^{1}$, apresenta saliências a esse respeito. A personagem da canção teve um sonho com seu companheiro e relata esse sonho para ele. Há tensão entre os dois, o que leva a acreditar que a personagem como que se confessa (religiosamente) diante do homem. $\mathrm{O}$ pecado, digamos pecado, poderia permanecer em segredo, mas não haveria com isso punição menor para a mulher sonhadora: o censor interiorizado praticamente obriga a punição a se extroverter. Inscrevendo o particular da arte no histórico de uma sociedade machista como é a nossa, poderemos aventar como a arte - no caso, as canções de Chico Buarque - colabora ou tensiona com o horizonte social. Para seguir a interpretação, acho importante retomar Freud, quando afirma que o sonho (como a fantasia, o ato falho e os chistes) é meio de vislumbrar o inconsciente em ação. O sonho, escreveu Freud (sem data), é a realização de um desejo, na presença de um censor, usando elementos do real e com prejuízo para esse ${ }^{2}$.

No caso da canção de Chico Buarque, o potencial revelador do sonho fica invertido: a sonhadora conta seu sonho para o próprio censor. Podemos entrever a atitude desse homem ao ouvir o que a sonhadora conta:

\section{Ai, amor, não briga}

Ai, não me castiga

Diz a mulher.

O sonho se torna uma reafirmação da censura. A sonhadora reforça essa "formação de compromisso":

\section{Ai, diz que me ama \\ E eu não sonho mais.}

A personagem da canção parece incapaz de ler seu inconsciente a não ser diante do censor, mas não precisamos ir até a personagem para dizer que a incapacidade de autocompreensão pode ser aberta em leituras cada vez mais abrangentes, que alcancem o modo como, atualmente, temos entendido o Brasil, por exemplo, em processos como o delirante

\footnotetext{
${ }^{1}$ Um dado importante: boa parte das canções em que há uma voz feminina construída em primeira pessoa fizeram parte de trilhas sonoras de filmes ou peças ou ainda foram partes de musicais. Todas as canções de Chico Buarque citadas aqui, e outras mais, estão disponíveis no site do autor, conforme referências.

${ }^{2}$ Trata-se aqui principalmente do capítulo III de A interpretação dos sonhos, quando Freud auto-analisa o famoso sonho com Irma.
} 
governo Collor, no início dos anos 1990. Algo como uma aliança entre o desejo e a instância recalcante se atualiza pela criação de um texto em que a figura repressora possa ser morta, mas não para que a sua morte, simbólica ou não, invista uma espécie de conhecimento. A morte da autoridade pode, pelo contrário, significar sua permanência como fantasma. Para que o machismo exerça sua opressão, se torna fundamental um texto, espécie de suporte repetitivo, em que a mulher diga seu "pecado" e o homem expurgue o "pecado" da mulher. O modo de expressar o pecado e o expurgo é violento, dramático, barroco.

A violência do sonho - que, não custa reforçar, é um sonho construído ficcionalmente - se expressa por um linchamento. A canção inteira não deixa de ser uma espécie de descrição do sonho enquadrada por um diálogo em que não se escuta a voz do homem, apenas a da mulher. O homem, contudo, ao ser aquele para quem a sonhadora dirige a palavra, habita o discurso dela, orientando as atitudes da sonhadora. Os dados que a canção entrega afirmam grande submissão da mulher, mas, é preciso sempre inverter essa construção, fazendo ver a opressão do homem sobre a mulher. O sonho, depois de tudo isso, explicita um desejo de opressão, o que faz retornar a velha divisa marxista: como é possível que tantas pessoas lutem pela própria opressão? Ou, em termos psicanalíticos: como é possível Eros demandar Tanatos, a destruição do $E u$ ser, para o próprio $E u$, um gozo de primeira ordem?

Tanto uma leitura psicanalítica, quanto uma leitura marxista da sonhadora que conta seu sonho ao repressor renderiam - em que pese a resistência que nos foi inculcada contra leituras psicologistas e sociologistas como se elas fossem conseqüências diretas apenas do conhecimento dos métodos de Freud e Marx - a hipótese de que houve na sonhadora uma identificação com a autoridade, que remonta a uma organização familiar edipiana, em que o pai foi arbitrário, talvez violento, estando ele também, o pai, submerso em discursos contra os quais ou a partir dos quais não conseguia erguer sua voz, seu Eu. Haveria um problema, de saúde, no caso psicanalítico, e de organização político-econômica, no caso marxista.

Escrevendo do modo como escrevi, tudo soa muito banal, até ridículo, mas me pergunto se não devo me questionar a respeito de por que perguntas - reiteração inevitável tão boas deveriam ser respondidas apenas de modo automatizado? Não foi devido (ou somente devido) a Freud e Marx que as análises marxistas e psicanalíticas passaram a permitir determinismos como aqueles descritos nos parágrafos acima. Lendo seus escritos, fica bastante claro que, no caso de Marx, ele exigia, atentava, apontava, sempre para a necessidade de se historicizar cada análise. Também Freud tinha cuidado em apontar seu trabalho como um trabalho em processo, tanto que, como sabemos, alterou sua tópica. 
Ora bem, o movimento do sonho indica um ciclo: $e u$ - bando - eu, em que o eu coincide (ou se dá justamente pela) com a presença do censor e em que o bando coincide com a morte do censor. Deixo ao leitor a tarefa de decidir se vale a interpretação de que o bando comete uma espécie de parricídio. Quando acorda, ao cair da cama, a sonhadora sente aquela que Freud descreve como a mais persistente das culpas, que fundamenta o que ele chamou de mal-estar na civilização (ou cultura) ${ }^{3}$. Além disso, haveria, creio eu, a possibilidade de dizer que ao retornar ao eu da vigília, a sonhadora impulsiona a lembrança da vida em bando. $\mathrm{O} e u$ ressente-se da prisão, da repressão, do esmagamento que é ser $e u$ e o sentimento de culpa redobra: culpa de ter assassinado o censor (ainda que em sonho) e culpa de regredir para a repressão (em vigília). A leitura marxista que se segue dessa leitura imanente é que a formação do $e u$, a repressão da mulher pelo homem, a constituição rebelde de um bando, tudo isso se inscreve na história, portanto, na luta de classes. O modo como a canção se estrutura é esboçado pela história e apenas por isso pode ser esteticamente elaborado pelo artista.

Tudo isso está muito bem e, como eu disse, o leitor deve estar à vontade para decidir se acolhe ou não a análise ou partes dela.

O caso é que se repete na obra de Chico Buarque, principalmente na obra anterior a 1980, isto é, aquela produzida no olho da ditadura, a figura da mulher que monologa e, ao monologar, inscreve no horizonte de seu discurso, um homem, não raro, uma espécie de algoz-amante ou amante-algoz. Chico Buarque constrói personagens suficientemente contraditórios para não serem estereótipos, mas ao mesmo tempo, (e não sei bem como escrever isso) recobre de estereótipo aquilo que parece profundo.

Entendo aí uma contradição na forma que marca a tarefa da presente análise. Chico Buarque, ao menos em algumas canções, nos conta a história de personagens que são personalidades singulares, mas que parecem, ao mesmo tempo, ter comprado sua individualidade na telenovela mais próxima. Quero ser bem entendido aqui: não me interessa dizer se isso é bom ou ruim, não me interessa prescrever como deveriam ser as personagens de uma canção ou de uma telenovela. Me interessa tentar compreender, analisar, estudar, rasurar o procedimento estético.

No caso de Não sonho mais, a personagem sonhadora parece não ter possibilidades objetivas para se tornar uma personalidade autônoma, dado o grau de introversão da autoridade repressora e o grau de dissolução necessário para ela se rebelar - dissolução que

\footnotetext{
${ }^{3}$ Além de $O$ mal-estar na civilização o tema pode ser estudado em, entre outros, Totem e tabu e Além do princípio do prazer. Usei a edição standard brasileira, publicada pela Imago, cf. bibliografia.
} 
chega a se inscrever num bando, que a sonhadora descreve como "um bando de orangotango". E ela diz mais:

\author{
Vinha nego humilhado \\ Vinha morto-vivo \\ Vinha flagelado \\ De tudo o que é lado \\ Vinha um bom motivo \\ Pra te esfolar
}

Há no subtexto dessa estrofe saliente identificação da personagem com esse bando de humilhados e ofendidos, animalizados pela situação. Ao se revoltarem e, com justiça, segunda a própria sonhadora, esfolarem a autoridade, "aquele povo/ Pôs-se a cantar". O canto, no caso, não é expressão lírica, ou seja, o canto de um eu. É, ao contrário, a expressão de um grupo, um bando, espécie de folclore, de ritual - mas um folclore sem tradição.

Espero não estar exagerando ao inventar uma diferença e até uma contradição entre as canções mais líricas de Chico Buarque e o cantar desse bando (que a canção não apresenta e que o ouvinte pode ou não imaginar). A diferença está justamente em que Chico Buarque é um eu quando canta - é lírico, portanto -; enquanto o bando não conseguiu individualização, porque a possibilidade para tanto está objetivamente interditada. De todo modo, o cantar de um grupo, o cantar folclórico, sem autoria, é uma das bases formais do samba, base que começou a ser alterada, se não estou enganado, a partir da implantação da indústria cultural no Brasil (SANDRONI, 2001). Ao surgir em Não sonho mais como um abismo que precisa ser imaginado pelo método crítico, a desigualdade entre o cancionista Chico Buarque e o existir do bando, entre o lirismo do cantor e a animalização de seus personagens humilhados, pode significar uma dobra nos horizontes estéticos dos artistas brasileiros, que tendem, a partir daí, muitas vezes, a expressar uma opressão por um dos signos que acaba por legitimar o poder que oprime. De um lado, o bando humano subtraído de si mesmo, que canta sua própria alienação, de outro, o humano que procura se autonomizar, se individualizar, que canta a busca de si. No começo do parágrafo falei em diferença. Mas aos poucos ficou claro que o problema aqui exposto não se marca mais por diferenças: as diferenças, na realidade brasileira, não podem ser entendidas sem uma dialética da desigualdade.

Dado isso tudo, não fica demais dizer que a sonhadora era incapaz de ler seu próprio sonho porque foi reprimida, negada, estilhaçada a sua possibilidade objetiva de ser $e u$. Na ilusão de sua individualização, inclusive, ela se envergonha e culpa, como ficou salientado. Abrangendo a questão: é impossível haver leitura sem a constituição de um eu, mas a constituição de um eu, no Brasil, ao longo da história (é diferente hoje?), se baseia na 
desigualdade entre as classes e nas contradições sociais, que estão, como preveria Adorno, marcadas na obra, não como espelhamento ou reflexo, é claro, mas como trabalho daquele eu que faz parte - inevitavelmente - da obra da desigualdade. Um canto lírico a respeito de um canto épico (o do bando) permite que vejamos na forma lírica a extorsão do conteúdo de vida dos flagelados, mortos-vivos e humilhados. Adorno os chamou de sem-sujeitos da história.

A partir dessas premissas, haveria muito a analisar em cada canção de Chico Buarque. O espaço do ensaio obriga uma escolha e a escolha é aquela que garante a coerência da apresentação: chama-se Tantas palavras, canção de Chico Buarque e Dominguinhos, datada de 1983. Por essa época, a televisão já não causava espanto, como acontecia, por exemplo, em canções dos anos 1960 (A televisão, de 1967, e Essa moça tá diferente, de 1969). As massacrantes importações de tecnologia e produtos da indústria cultural ao longo do período de ditadura militar se estabeleceram em uma sociedade em que não houve democratização da educação de base. O que acontece, então, é que os produtos da indústria cultural não encontram um público leitor, constituído por "mônadas burguesas". Trata-se de um público em grande parte inserido em meios folclóricos que passa, de repente, a lidar com o cinema, a rádio, a televisão, a cidade. Como diz Celso Furtado (1990):

A substituição do cavalo pelo automóvel não é apenas uma evolução do sistema de transporte: é a transformação de um estilo de vida. Falar de difusão ou transmissão de tecnologia é, portanto, um eufemismo, pois o que se está difundindo nesse caso é uma forma de viver, o que implica a desarticulação do sistema de valores preexistentes na sociedade receptora das novas técnicas. (FURTADO, 1990, s.p.)

Com as grandes migrações que alimentaram de mão-de-obra forçada ou induzida os inúmeros "planos" de "modernização" do país, houve sucessivos deslocamentos e o total impedimento de que as pessoas pudessem retomar ou reinventar, nas cidades, suas expressões folclóricas e rurais. Ao juntar Dominguinhos e Chico Buarque, a música popular brasileira segue uma proposição de fundo, em que folclore vira autoria e individualidade, sem que haja, necessariamente, vacilação crítica diante do processo, pelo contrário, havendo sempre um elogio do folclore prensado em disco, recortado de todo o processo que o tornou disco.

Tantas palavras têm duas versões. A primeira foi trilha sonora da novela Sabor de mel, de 1983; a segunda foi gravada no LP Chico Buarque, de 1984. É essa a versão que diz:

\author{
Tantas palavras \\ Que ela gostava \\ E repetia \\ Só por gostar \\ Não tinham tradução \\ Mas combinavam bem \\ Toda sessão ela virava uma atriz
}




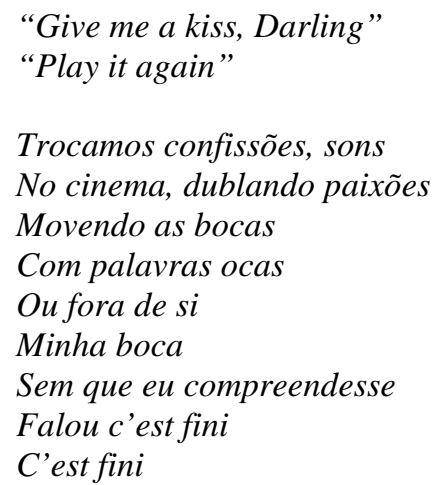

Como está claro, as duas personagens, apresentadas pela visão de uma delas (um homem), falam o que não sabem. São quase papagaios. As confissões não se realizam, reduzida que foi a linguagem a "sons" e, como numa canção recente do mesmo Chico Buarque $^{4}$, a mulher vive como atriz, agindo como que possuída por fantasmas. Mas quem não atua?, poderá perguntar alguém. Verdade, quem não atua? O problema é que, como percebeu Paulo Freire, o que aprendemos é tanto mais profícuo, rebelde e modificador, quanto mais ligado for aos problemas postos pelo dia-a-dia. Quando o dia-a-dia é produzido e a "realidade" não pode mais auferir a validade dos discursos, então não se pode estar satisfeito em atuar de qualquer modo, sob o risco de agir de modo esquizofrênico, como as personagens de Chico Buarque, e sob o risco de atuar nossa própria dominação, com gozo e delícia. Nesse caso, fica mais visível porque o compositor opta de forma tão recorrente a utilizar "estereótipos-individualizados": de algum modo, lidar com a possibilidade de estabelecer um $e u$ ilusório, subtraído de identificações e projeções de fato, para estabelecê-las em delírio alienado, é lidar com um modo de ser do Brasil contemporâneo (do planeta inteiro?). Portanto, a leitura do mundo - como na concepção de Paulo Freire (1994) - coincide com uma leitura de si e, nesse sentido, tanto Freud quanto Marx ainda têm muito a nos dizer, sobretudo quando os eus que se erguem contra as pulsões historicamente organizadas são possibilitados também pelas e apesar das desigualdades. Assim, identificações organizadas conforme os modos de produção e circulação do capital transnacional fomentam pulsões que nos levam a acreditar, muitas vezes, na inocência das identificações e das projeções, das atuações, enfim, que são barreiras objetivas na construção de eus habilitados para construir sua vida com autonomia e cooperação.

Há aí, quem sabe, um problema a respeito do estatuto da mimese. Os filmes, a televisão, o rádio, tudo parece dizer: "eis a realidade como é, como deve ser e como sempre será” (HORKHEIMER apud ROUANET, 1989, p. 138). As relações sociais, porém, indicam

\footnotetext{
${ }^{4}$ Ela faz cinema, do CD Carioca, de 2006.
} 
outra realidade - ou mesmo não indicam mais. A mimese dos objetos artísticos não coincide com os ritmos, problemas, ciclos, relações e necessidades dos indivíduos e comunidades, que, no entanto, passam a compreender a si mesmos a partir, entre outras processos, dessa mimese vesga feita pela indústria cultural. Fragmentação, destotalização, polifonias, podem, então, ser efeitos de sentido de um modo de circulação do capital - além de modos renovadores da arte, como geralmente são apresentados. A luta contra os totalitarismos não pode se afirmar fechando os olhos para a totalização pelo lucro.

Voltando à canção, veremos que as sucessivas identificações das personagens financiam, com o pagamento de ingressos, um jogo de espelhamento - marcado pelas ideologias do lucro - no qual o que restam são palavras ocas, sons abstraídos de qualquer sentido e a incomunicabilidade pela palavra. Não há leitura, outra vez, apenas repetição.

Voltando no tempo, para 1969, encontramos uma canção que mimetiza o processo histórico em que a televisão deixa de ser um produto para as classes médias e altas e se "democratiza". Essa moça tá diferente conta a história que se repete de vez em vez na obra do compositor: uma garota, geralmente pobre, que, de repente, muda. Dessa linhagem, Quem te viu, quem te vê talvez seja o exemplo mais famoso e bem acabado. Em Essa moça, mais uma vez, é a mulher, não o homem, quem muda (la donna è móbile?), quem assiste televisão, quem se entrega a um modo de vida que não seria o seu ou não deveria ser. Nesse caso, a mulher se torna troféu em que uma classe ostenta seu poder. Um produto (e a publicidade contemporânea não parece ver problema em admitir, com desfaçatez, essa atitude) que presta o serviço de anular seu desejo para que o capital torne-se gozo ali; isto é, a mulher se torna comprável, vendível e o sadismo que muitos homens sentem nessa anulação é prazer estético quando reposto para a arte. Não são poucos que entendem na vertigem do capital pelo corpo da mulher a liberação (da sexualidade) feminina. E é "liberação" um dos temas de Essa moça:

\footnotetext{
Essa moça tá decidida

A se supermodernizar

Ela só samba escondida

Que é pra ninguém reparar

(...)

Ela quer ver o astronauta

Descer na televisão
}

Pode-se dizer que, de forma nada desprezível, o desejo descrito como feminino em nossas sociedades tem sido aquele que se anula, um desejo que é desejo "de se entregar". Estranho desejo, constituído por sua própria anulação (diante do homem ou da publicidade ou do capital). Onde há infinidades e singularidades em processo, as representações não raro criam uma essência - a mulher como sempre deveria ter sido. 
A relação entre mulheres e cultura de massa não é nova (HUYSSEN, 1996). Madame Bovary exemplifica esse clichê, ou quase-clichê, da literatura ocidental, que expõe aos nossos olhos um machismo constitutivo de dualidades que informam o modo de ver o mundo de muitos autores modernos. Assim, o homem seria aquele que sabe o que ler, enquanto a mulher não saberia o que ler, nem como ler ${ }^{5}$.

(...) a mulher (Madame Bovary) é apresentada como uma leitora de literatura inferior subjetiva, emocional e passiva -, enquanto o homem (Flaubert) emerge como um escritor da genuína e autêntica literatura - objetivo, irônico e com o controle de suas formas estéticas. Sem dúvida, tal posição da mulher como consumidora de literatura massificada, que encaro como paradigmática, também afeta a mulher escritora que tem o mesmo tipo de ambição do "grande (homem) modernista. (HUYSSEN, 1996, p. 43)

Se compreendi bem, passa por esse clichê a arquitetura da personagem de Meu guri, de 1981. Trata-se de uma mãe que não entende as atividades de seu filho, inscrevendo-as em uma santificação idealizada do menino, para ela trabalhador e esforçado.

\author{
Chega suado e veloz do batente \\ E traz sempre um presente pra me encabular \\ Tanta corrente de ouro, seu moço \\ Que haja pescoço pra enfiar \\ Me trouxe uma bolsa já com tudo dentro \\ Chave, caderneta, terço e patuá \\ Um lenço e uma penca de documentos \\ Pra finalmente eu me identificar
}

A voz do filho (ou de algo como um arquétipo daquele filho) se revela em Minha história, da época que Chico Buarque passou no exílio italiano. Nessa canção, um rapaz lembra de sua mãe, pobre e esfarrapada, esperando pelo seu homem (que tinha tatuagem no braço e dourado no dente).

\title{
Ele assim como veio partiu não se sabe pra onde \\ E deixou minha mãe com o olhar cada dia mais longe \\ Esperando, parada, pregada na pedra do porto \\ Com seu único velho vestido cada dia mais curto
}

A diferença entre a visão do filho e a visão da mãe é que o filho aparentemente compreende o que viu e sabe colocar seu discurso em consonância com a experiência vivida, ao passo que a mãe constrói seu entendimento com singelos e delirantes equívocos. A ingenuidade dessas mulheres (as das duas canções) não pode ser lida com um riso nem ser justaposta por completa identificação. Meu guri, por exemplo, é um caso em que o rebaixamento da personagem não serve para a comédia, criando uma espécie de

\footnotetext{
${ }^{5}$ A esse respeito acho importante citar um livro que li depois de escrever esse artigo, mas que acrescentaria imensamente o potencial dessa discussão. Trata-se de A formação da leitura no Brasil, de Maria Lajolo e Regina Zilberman, cf. bibliografia.
} 
engrandecimento pela diminuição. Tenho a impressão que poucos de nós conseguem ainda remeter uma canção à decadência de toda uma forma de organização social, mesmo porque seria exagero, nesse caso. Mas, em contrapartida, muitas vezes tendemos a como que alienar a canção e vê-la como uma proeza estética que deve ser elogiada, estudada e compreendida em seus efeitos. A proeza estética, contudo, não amacia a leitura crítica que evidencia a recorrência da idéia de que mulheres não sabem ler o mundo, enquanto os homens o fazem de forma adequada.

Isso nos leva ao caso de Mulheres de Atenas (1976). Ali, parece, o argumento de HUYSSEN (1996) - exposto acima - abre frentes para discussões. A ironia da letra, a arquitetura cuidadosa, o vocabulário raro, a referência à literatura de Homero (interditada para a maior parte dos brasileiros), tudo denota um eu-lírico absolutamente desigual em relação às mulheres e, em certo sentido, se levarmos em conta o efeito da canção, um eu superior em relação às mulheres, tomadas como um todo. A canção não teria significado algum numa realidade sem repressão, em que a mulher e o homem se marcassem pelas suas diferenças e não pelas suas desigualdades. A voz da canção é quase que automaticamente ligada a um homem, até porque se dirige às mulheres com imperativos: Mirem-se! Não deve ficar de todo negada a possibilidade de ler uma mulher como a voz da canção ou a possibilidade de que alguma cantora a possa cantar reinvestindo a ironia já presente, fazendo-a voltar para os homens: Mirem-se no exemplo daquelas mulheres de Atenas ou ainda, fazendo-a anular-se quando dirigida de uma mulher para as próprias mulheres (mas a anulação da ironia viria acompanhada por uma literaridade da opressão sofrida pelas mulheres e não por um enfraquecimento ou emburrecimento da interpretação). As marcas de que um homem fala na canção são discursivas; não há uma só marca lingüística da presença de uma voz eminentemente masculina. No entanto, parece impossível, para que a ironia funcione, que uma mulher fale ali. O feminino na canção está marcado pelo seu silenciamento e pelo seu encarceramento em níveis precisos de significação, como se masculino e feminino tivessem sentidos precisos, imediatamente reconhecíveis e legitimados.

A leitura do mundo não está somente interditada para as mulheres, a leitura das mulheres se vê por sua vez trancafiada na ingenuidade, na tolice. A esse respeito, mas a propósito de outra coisa, Roswitha Scholz (2005) escreveu:

determinadas qualidades, atitudes e sentimentos avaliados como menores (sensualidade, emocionalidade, fraqueza de carácter e de entendimento, etc.) são projectados sobre "a mulher" e dissociados pelo sujeito masculino, que se constrói como forte, realizador, concorrencial, eficiente e por aí fora. Por isso também tem de ser levada em consideração a correspondente dimensão sócio-psicológica, bem como a dimensão cultural-simbólica, com o 
que o patriarcado produtor de mercadorias há-de ser apreendido como modelo civilizacional, e não apenas como um sistema económico. (SCHOLZ, 2005, s.p. )

E isso, apesar de todos os discursos, ou sobretudo devido a eles, se faz presente hoje, nas contradições da forma de um artista como Chico Buarque. Trata-se, portanto, de um problema atual: a repressão da mulher como singularidade inapreensível por clichês cerrados é ainda uma realidade; talvez tenha, em determinados contextos, mudado de forma, mas está aí, agindo como nunca.

Por fim, não deixa de ser sintomático que Chico Buarque seja entendido como um compositor que entende "a alma feminina", frase que se pode ouvir seguidamente, dita por mulheres e homens, nos jornais, nas academias (de ginástica), nos bares, boates etc. Sintomático porque marca a concordância, de homens e mulheres, com os procedimentos de compreensão da mulher por meio de algumas idéias-clichês, que perpassam a literatura do ocidente ao oriente, e que perpassam também discursos machistas e misóginos, como os de Nietzsche. Penso que as interpretações que construí esboçam uma problematização da identificação entre "a alma feminina" e as canções de Chico Buarque - riscando no quadro estético questões políticas e econômicas; problematizando também o nada desprezível fato de que seja um homem, Chico Buarque, o designado para "entender" as mulheres e colocando em dúvida, por fim, a racionalidade do homem, agora, que assina este artigo.

\section{Referências}

ADORNO, Theodor. Wiesengrund. Minima moralia: reflexões a partir da vida danificada. São Paulo: Ática, 1993.

BUARQUE, Chico. Canções.

Disponível em: http://chicobuarque.uol.com.br/construcao/index.html. Acesso em $15 / 02 / 2008$.

CANDIDO, Antonio. Vários escritos. São Paulo: Duas cidades, 1995.

FERNANDES, Florestan (org.). K. Marx, F. Engels: história. São Paulo: Ática, 1984.

FREIRE, Paulo. Pedagogia da esperança. Rio de Janeiro: Paz e Terra, 1994.

FREUD, Sigmund. Totem e tabu. In:___ Edição standard brasileira das obras psicológicas completas de Sigmund Freud. Rio de Janeiro: Imago, vol.13, p.13-193, 1987.

Além do princípio de prazer. Rio de Janeiro: Imago, 1998. 
O mal-estar na civilização. Rio de Janeiro: Imago, 2002.

HUYSEEN, Andreas. Memórias do modernismo. Rio de Janeiro: UFRJ, 1996.

JAMESON, Fredric. Marxismo e forma: teorias dialéticas da literatura no século XX. São Paulo: Hucitec, 1985.

LAJOLO, Marisa \& ZILBERMAN, Regina. A formação da leitura no Brasil. São Paulo: Ática, 1996.

ROUANET, Sérgio Paulo. Teoria crítica e psicanálise. Rio de Janeiro: Tempo brasileiro, 1989.

SANDRONI, Carlos. Feitiço decente: transformações do samba no Rio de Janeiro (19171933). Rio de Janeiro: Jorge Zahar, 2001.

SANTIAGO, Silviano. L'avenir de l'homme est la femme. In: As raízes e o labirinto da América Latina. Rio de Janeiro: Rocco, 2006.

SCHMIDT, Rita Terezinha (org.). Mulheres e literatura: (trans)formando identidades. Porto Alegre: Editora Palloti, 1997.

SHOLZ, Roswitha. A nova crítica social e o problema das diferenças: disparidades económicas, racismo e individualização pós-moderna. Algumas teses sobre o valordissociação na era da globalização. Original Neue Gesellschaftskritik und das Problem der Differenzen. Ökonomische Disparitäten, Rassismus und postmoderne Individualieserung. Einige Thesen Zur Wert-Abspaltung in der Globalisierungsära. Revista EXIT! No 1, Agosto de 2004. NAHODIL, Lumir (Trad.). ANTUNES, Boaventura (rer.) Disponível em: http://antivalor.vilabol.uol.com.br. Acesso em: 11/12/2007. 